\title{
EVALUASI GEOMETRI JALAN ANGKUT BATUBARA DARI FRONT KE STOCKROM PADA PIT 6 TERHADAP KETERCAPAIAN PRODUKSI DI PT XYZ
}

\author{
THE EVALUATION OF COAL HAULING ROAD GEOMETRY FROM \\ FRONT TO STOCKROM AT PIT 6 ON THE PRODUCTION ACHIEVEMENT AT PT XYZ
}

\author{
Sepriadi ${ }^{1)}$, Aji Stiandi ${ }^{2}$ \\ ${ }^{1,2)}$ Program Studi Teknik Pertambangan Politeknik Akamigas Palembang, 30257, Indonesia \\ Corresponding Author E-mail: sepri@pap.ac.id dan ajistiandi11@gmail.com
}

\begin{abstract}
PT XYZ is a company engaged in coal mining and the sole contractor of PT KLM. The mining system carried out by PT XYZ was an open pit mining system or surface mining and the method used was conventional mining. The objective of this research is to determine the geometry of the coal hauling road such as haul road width, road slope, cycle time and cross slope. The method used in this study was quantitative method; the method is a scientific and systematic method based on theoretical foundations. The results of the observations were the actual conditions in the field, for the average width of the straight hauling road was 10 meters from the front to the stockroom and on bends an average was 11 meters, but based on the calculation by The American Association of State Highway and Transport Officials (AASTHO) Manual Rural Highway Design 1973, the minimum width for straight roads was 8.715 meters and bend roads was 9 meters. Based on the field, the straight roads which did not meet the minimum road standards were Segment N-O and T-U and the bend roads were Segment $\mathrm{W}$-Stockrom. The cycle time from front to the stockrom in Pit 6 was fairly long caused by the straight hauling roads in Segment N - O and Segment T - U and the bend road Segment W - Stockrom and the stockpiling of coal hauling road coating resulted on the travel time (cycle time) of the hauling tools longer, namely 19.21 minutes, after conducting the road improvement by increasing the width of the straight hauling road by 8.715 meters and at the bend by 9 meters and the process of stockpiling the hauling road coating becomes shorter by 14.78 minutes with the resulted production of 52,047.451194 tons/month.
\end{abstract}

Keywords: Geometry, Segment, Cycle Time, Production

Abstrak: PT XYZ, adalah salah satu perusahaan yang bergerak di bidang pertambangan batubara dan kontraktor tunggal dari PT KLM. Sistem penambangan yang dilakukan oleh PT XYZ adalah sistem tambang terbuka atau surface mining dan metode yang digunakan, adalah konvensional mining. Tujuan penelitian yakni untuk mengetahui geometri jalan angkut batuabara seperti: lebar jalan angkut, kemiringan jalan, waktu edar (cycle time), cross slope. Metode yang digunaka pada penelitian ini menggunakan metode kuantitatif adalah metode secara ilmia dan sistematis berdasarkan landasan teori-teori. Hasil dari pengamatan adalah Kondisi aktual di lapangan untuk lebar jalan angkut lurus rata-rata 10 meter dari front ke stockroom dan pada tikungan rata-rata 11 meter, namun berdasarkan perhitungan The American Association of State Highway and Tronsportation Officials (AASTHO) Manual Rural Highway Design 1973, untuk jalan lurus lebar minimum adalah 8,715 meter dan untuk jalan tikungan, adalah 9 meter. Berdasarkan di lapangan untuk jalan lurus yang belum memenuhi standar jalan minimum terdapat segmen $N$ - O dan $T-U$ dan untuk jalan tikungan terdapat pada segmen $W$ - stockrom. Untuk (cycle time) dari front ke stockrom pada pit 6 memiliki waktu edar yang cukup lama yang disebabkan oleh adanya jalan angkut lurus segmen $N-O$ dan $T-U$ dan jalan tikungan terdapat pada segmen $W$ - stockrom dan penimbunan pelapisan jalan angkut batubara, mengakibatkan waktu tempuh (cycle time) alat angkut menjadi lebih lama yaitu 19,21 menit, setelah dilakukan perbaikan jalan dengan menambah lebar jalan angkut lurus sebesar 8,715 meter dan pada tikungan sebesar 9 meter dan proses penimbunan pelapisan jalan angkut batubara maka waktu tempuh menjadi lebih singkat sebesar 14,78 menit dengan produksi yang dihasilkan sebesar 52.047,451194 ton/bulan.

Kata kunci : Geometri, Segmen, Cycle Time, Produksi

\section{PENDAHULUAN}

\subsection{Latar Belakang}

PT XYZ merupakan salah satu perusahaan yang bergerak di bidang pertambangan batubara, PT XYZ adalah kontraktor tunggal dari PT KLM. Sistem penambangan yang dilakukan oleh XYZ adalah sistem tambang terbuka dan metode yang digunakan, yaitu conventional mining merupakan kombinasi dari alat angkut dump 
truck Hino 500 Ranger dan alat muatnya, yaitu excavator Komatsu 330 GC.

Operasi penambangan sangat membutuhkan jalan tambang sebagai sarana infrastruktur yang sangat penting di dalam lokasi penambangan Jalan tambang di PT XYZ terbagi menjadi 3 jalan, yaitu jalan produksi overburden berjarak \pm 250 meter dari pengupasan overburden ke disposal, jalan produksi batubara atau jalan hauling batubara dari front ke stockrom yang berjarak 2.500 meter serta jalan hauling batubara dari stockrom menuju stockpile atau pelabuhan. Hal ini yang mengharuskan jalan hauling selalu dalam keadaan baik setiap saat agar dapat memperlancar proses produksi batubara sesuai dengan target produksi.

\subsection{Batasan Masalah}

Batasan masalah dalam penelitian tugas akhir ini, penulis membatasi dan memfokuskan penelitian terhadap geometri jalan angkut batubara, seperti: lebar jalan angkut pada lajur lurus maupun tikungan, kemiringan memanjang atau grade jalan angkut batubara, kemiringan melintang (cross slope) jalan angkut batubara, serta upaya yang harus dilakukan untuk mengurangi kemungkinan kecelakan dan peningkatan produksi batubara dan dapat memperbaiki waktu edar atau (cycle time) alat angkut dump truck Hino 500 Ranger untuk mengurangi ketidaktercapaian produksi batubara di PT XYZ.

\subsection{Tujuan Penelitian}

1. Mengevaluasi geometri jalan hauling batubara seperti : lebar jalan angkut pada lajur lurus maupun tikungan, kemiringan memanjang atau grade kemiringan melintang (cross slope) yang berdampak pada keberhasilan produksi batubara sesuai rencana di PT XYZ.

2. Mengetahui cara yang diperlukan untuk memperbaiki dan mempertahankan geometri jalan angkut batubara sehingga dapat mengecilkan dan mengurangi tingkat kecelakaan dan di PT XYZ.
3. Memperbaiki waktu edar (cycle time) alat angkut dump truck Hino 500 Ranger agar dapat mengurangi ketidaktercapaian produksi batubara di PT XYZ.

\subsection{Manfaat Penelitian}

Manfaat yang diharapkan dari penelitian ini sebagai berikut :

1. Dapat mengetahui geometri jalan angkut batubara di PT XYZ.

2. Dapat mengetahui cara yang diperlukan untuk memperbaiki geometri jalan angkut batubara agar dapat mengurangi kemungkinan kecelakaan di PT XYZ.

Dapat mempersingkat waktu edar (cycle time) alat angkut dump truck Hino 500 Ranger agar dapat mengurangi ketidaktercapaian produksi batubara di PT XYZ.

\section{TEORI DASAR}

\subsection{Definisi Jalan Hauling Road}

Definisi jalan berdasarkan Undangundang Republik Indonesia Nomor 13 Tahun 1980 menjelaskan bahwa jalan adalah suatu prasarana perhubungan darat dalam bentuk apapun meliputi segala bagian jalan termasuk bangunan pelengkap dan perlengkapannya yang diperuntukkan bagi lalu lintas. Bangunan pelengkap dan perlengkapan jalan, yaitu bangunan atau aksesoris jalan, misalnya lampu jalan, rambu-rambu lalu-lintas dan lain-lain.

Jalan tambang batubara merupakan jalan khusus yang dibuat oleh perusahaan tambang untuk kepentingan-kepentingan kegiatan pertambangan misalnya: jalan produksi overburden digunakan untuk mengangkut overburden dari pengupasan overburden ke disposal dan jalan hauling batubara digunakan untuk mengangkut batubara dari front ke stockrom.

\subsection{Faktor-faktor yang Perlu Diperhatikan Dalam Geometri Jalan}

Faktor-faktor dalam geometri jalan hauling batubara ada beberapa hal yang perlu diperhatikan agar dapat memaksimalkan fungsi dari jalan hauling batubara dan juga keselamatan dari pengguna jalan tersebut, yaitu :

\subsubsection{Lebar Jalan Pada Lajur Lurus}


Perhitungan pada jalan lajur lurus menggunakan acuan rumus menurut AASHTO manual rural high way design 1973, perhitungan pada jalan lajur lurus dan jalan lajur tikungan memiliki perbedaan, yakni jika pada jalan lajur tikungan alat angkut akan membutuhkan ruang gerak yang lebih lebar karena jejak roda depan dan roda belakang yang ditingalkan di atas jalan kendaraan yang melebar. Maka dari itu, lebar jalan minimum pada jalan lajur lurus menurut AASHTO manual rural high way design 1973, harus ditambah dengan setengah lebar alat angkut pada bagian tepi kiri dan tepi kanan.

Maka dari itu, kita dapat menggunakan cara di atas untuk menentukan lebar jalan angkut minimum sebagai berikut:

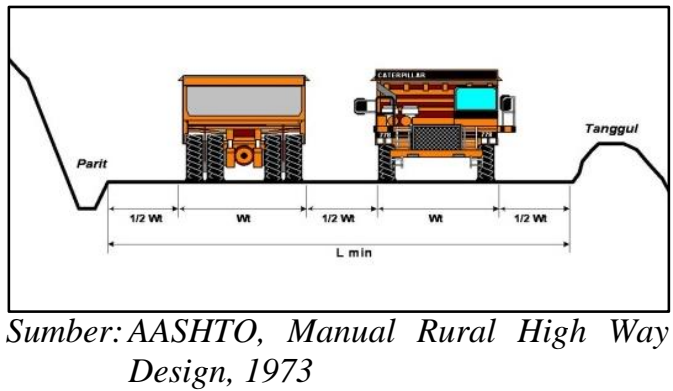

Gambar 2.1 Jalan Lurus

\subsubsection{Lebar Jalan Pada Lajur Tikungan}

Menentukan lebar jalan tikungan berbeda dengan menentukan lebar jalan lajur lurus karena di jalan tikungan berdasarkan pada lebar jejak roda, lebar jejak roda pada bagian depan dan pada bagian belakang pada saat kendaraan berbelok, jarak antara kendaraan dengan kendaraan lainnya saat berbelok dan jarak dari kedua tepi jalan. Lebar jalan pada lajur tikungan gambar 2.2

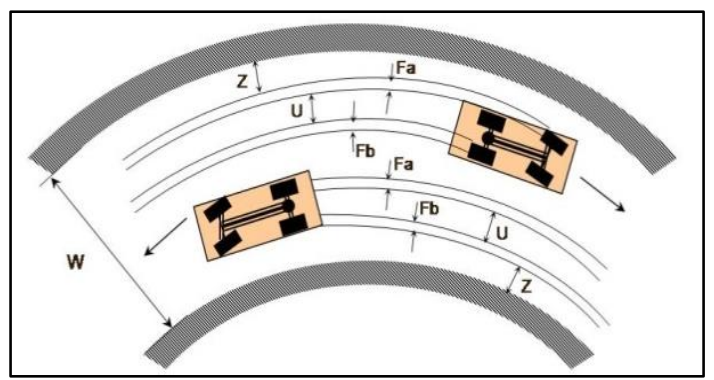

Sumber: Ir. Yanto indosesianto, M.Sc. 2013

Gambar 2.2 Jalan Tikungan

\subsubsection{Kemiringan Melintang (Cross Slope)}

Kemiringan melintang (cross slope) merupakan sudut yang dibentuk oleh dua sisi permukaan jalan terhadap bidang horizontal, tujuan dibuatnya (cross slope), yaitu ketika turun hujan maka air hujan tersebut bisa mengalir ke sisi-sisi dari jalan atau ke paritparit pada jalan agar air hujan tersebut tidak tergenang di jalan tambang dan tidak membahayakan pengguna jalan tambang tersebut. Menurut Silvia Sukirman, cross slope ideal pada jalan lurus sebesar 1/50 s.d. 1/25 (20 s.d. 40 mm/m). Menurut Kep.Men ESDM No. 1827 K/30/MEM/2018 yang berisi sepanjang permukaan badan jalan tambang dibentuk kemiringan melintang (cross slope) paling kurang $2^{\circ}$

\subsection{Kemiringan Memanjang Jalan (Grade)}

Kemiringan memanjang jalan (grade) merupakan tanjakan ataupun turunan yang disebabkan perbedaan ketinggian pada daerah atau lokasi jalan tersebut. Kemiringan jalan angkut ini biasa berpengaruh pada produksi karena menimbulkan tahanan tanjak (grade resistance).

Menurut Kep.Men ESDM No. 1827 $\mathrm{K} / 30 / \mathrm{MEM} / 2018$ yang berisi kemiringan jalan (grade) jalan tambang/produksi dibuat tidak boleh melebihi $12 \%$ (dua belas persen) dengan memperhitungkan: spesifikasi kemampuan alat angkut, jenis material jalan dan fuel ratio penggunaan bahan bakar.

Kemiringan 1\% merupakan kemiringan permukaan menanjak atau menurun secara vertikal dalam jarak horizontal 100 meter. Untuk mengetahui kemiringan jalan dapat menggunakan persamaan sebagai berikut (Prodjosumarto, 1993):

$$
\text { Grade }=\frac{\Delta \mathrm{h}}{\Delta \mathrm{x}} \times 100 \%
$$

Dimana: $\Delta \mathrm{h}=$ beda elevasi $(\mathrm{m})$

$$
\Delta \mathrm{x}=\text { jarak horizontal }(\mathrm{m})
$$

\subsection{Tanggul Keselamatan Jalan Angkut Tambang}

Tanggul keselamatan jalan angkut tambang, yaitu tanggul yang dibuat sepanjang sisi jalan atau di kedua sisi jalan yang berfungsi agar dapat menahan dan melindungi 
kendaraan angkut batubara yang keluar dari jalur jalan.

Menurut Kep.Men ESDM No. 1827 K/30/MEM/2018 yang berisi pada setiap jalan tambang/produksi tersedia tanggul pengaman di sisi luar badan jalan dengan tinggi sekurang-kurangnya $3 / 4 \quad$ (tiga $\quad$ per empat) diameter roda kendaraan terbesar dan memperhitungkan potensi air limpasan dan/atau material lepas yang dapat masuk ke jalan.

\subsection{Cycle Time Alat Angkut Batubara}

Cycle time alat angkut batubara merupakan waktu edar atau waktu tempuh yang dimiki alat angkut dimulai dari delay, maneuver loading, loading, hauling isi, maneuver dumping, dumping, dan hauling kosong. Satu siklus ini lah yang disebut sebagai cycle time.

\subsection{Rimpul Alat Angkut}

Rimpull merupakan kekuatan atau tenaga dari mesin alat angkut yang diberikan kepada permukaan jalan atau diberikan kepada roda penggeraknya yang menyentuh permukaan jalan. Satuan rimpul dinyatakan dalam pounds (lbs) dan dapat dihitung menggunakan rumus sebagai berikut (Prodjosumarto, 1993):

$$
\begin{aligned}
\text { Dimana: } \mathrm{RP} & =\text { rimpull }(\mathrm{lb}) \\
\mathrm{HP} & =\text { daya mesin }(\mathrm{HP}) \\
\mathrm{Eff} & =\text { efisien mesin } \\
\mathrm{V} & =\text { kecepatan }(\mathrm{mph})
\end{aligned}
$$$$
\mathrm{RP}=\frac{375 \times \mathrm{HP} \times \mathrm{Eff}}{\mathrm{v}}
$$

\subsection{Grade Resistance}

Grade resistance merupakan besarnya gaya berat yang melawan atau membantu gerak kendaraan. Oleh karena itu, jika permukaan jalan itu menanjak, maka grade resistance akan melawan gaya yang ada di kendaraan dan permukaan jalan yang menanjak disebut dengan positif. Sebaliknya jika permukaan jalan yang dilalui oleh kendaran menurun, maka akan membantu kendaraan tersebut dan permukaan jalan yang menurun disebut negatif. Tiap-tiap kemiringan jalan akan memperngaruhi dari grade resistance tersebut.

\subsection{Rolling Resistance (RR)}

Rolling resistance adalah tahanan gelinding atau gulir yang terdapat pada roda kendaraan yang bergerak di atas permukaan tanah yang mengakibatkan gesekan antara perrmukaan ban kendaraan dengan permukaan jalan yang saling berlawanan. Untuk menentukan perhitungan rolling resistance dapat menggunakan persamaan berikut (Prodjosumarto, 1993):

$$
\mathrm{RR}=\mathrm{W} \cdot \mathrm{r}
$$

Dimana: $\mathrm{RR}=$ rolling resitance $(\mathrm{lb})$

$$
\begin{aligned}
\mathrm{W}= & \text { gross veicle weight }(\text { ton }) \\
\mathrm{r}= & \text { koefesien rolling resistance } \\
& (\mathrm{lb} / \mathrm{ton})
\end{aligned}
$$

\subsection{Perhitungan Jarak, Waktu dan Kecepatan}

Untuk menghitung besarnya kecepatan dapat menggunakan persamaan berikut :

$$
\mathrm{v}=\frac{\mathrm{s}}{\mathrm{t}}
$$

Dimana: $\mathrm{v}=$ kecepatan $(\mathrm{m} / \mathrm{s})$

$$
\begin{array}{ll}
\mathrm{s} & =\text { jarak }(\mathrm{m}) \\
\mathrm{t} & =\text { waktu tempuh }(\mathrm{s})
\end{array}
$$

\subsection{Swelling Factor}

Swelling factor adalah faktor pengembangan material yang merupakan perbandingan antara volume material dalam keadaan insitu (belum digali $=\mathrm{BCM}$ ) dan volume material dalam keadaan loose (telah digali $=$ LCM). Besarnya swell factor dapat dihitung dengan persamaan berikut :

$$
\mathrm{SF}=\frac{\mathrm{Vb}}{\mathrm{Vl}} \times 100 \%
$$

Dimana: $\mathrm{SF}=$ swelling factor

$$
\begin{aligned}
\mathrm{Vb} & =\text { volume material bank }\left(\mathrm{m}^{3}\right) \\
\mathrm{Vl} & =\text { volume material loose }\left(\mathrm{m}^{3}\right)
\end{aligned}
$$

\section{METODOLOGI PENELITIAN}

\subsection{Jenis Penelitian}

Keberadaan kondisi jalan angkut hauling batubara antara front dengan stockrom di tambang PT XYZ dicari dengan menggunakan metode penelitian kuantitatif, yaitu penelitian secara langsung dan dilakukan observasi langsung ke lapangan. Untuk menunjang hal ini, maka dilakukan pengamatan di lokasi jalan tambang, pencatatan data untuk memperoleh geometri jalan tambang, ukuran jalan serta lebar jalan, 
keadaan elevasi jalan, keadaan cross slope jalan tambang.

\subsection{Waktu dan Tempat Penelitian}

Penelitian ini dilakukan pada bulan April tahun 2021 di PT XYZ.

\subsection{Bagan Alir Penelitian}

Metode penelitian yang digunakan dalam peneleitian ini seperti pada gambar 3.1 ini adalah:

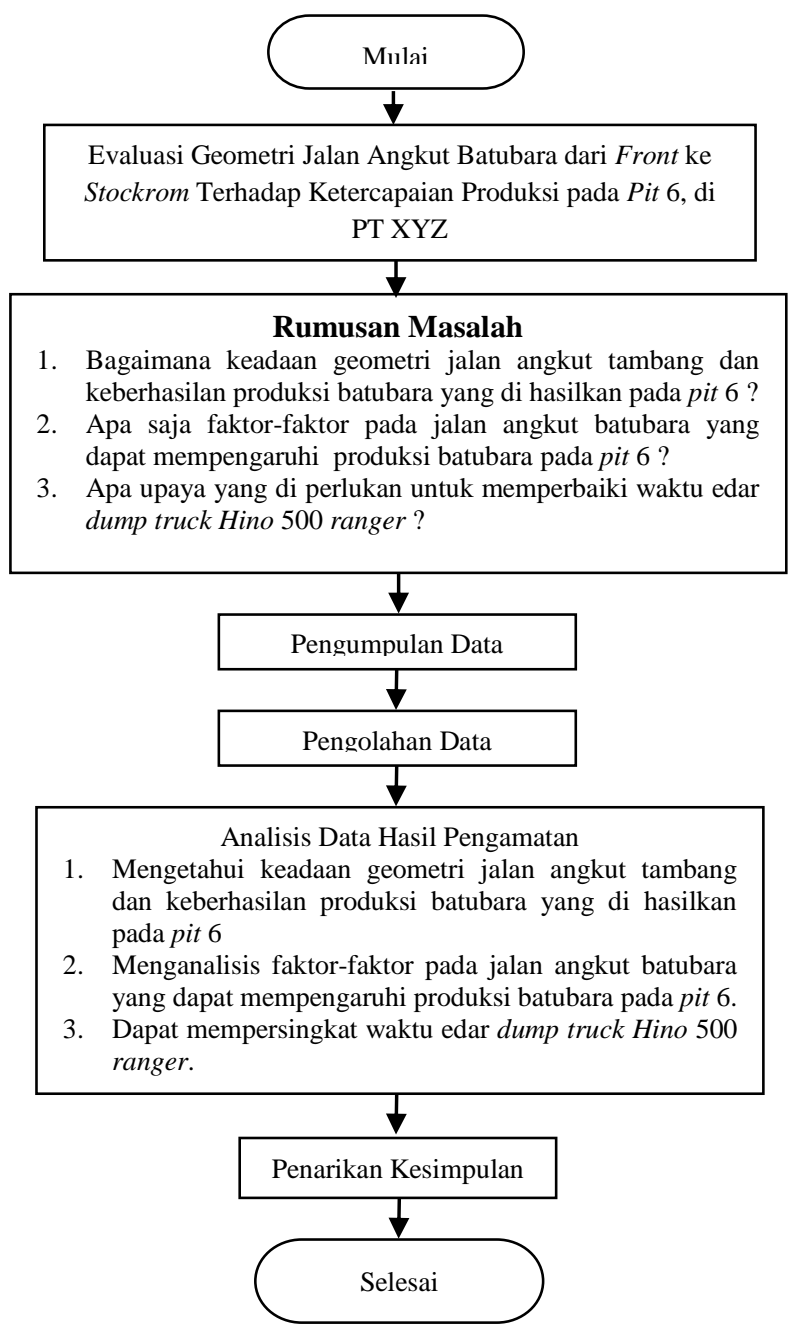

Gambar 3.1 Bagan Alir Penelitian

\subsection{Metode Penelitian}

Pokok permasalahan yang ditentukan untuk tujuan yang ingin dicapai dengan diadakanya penelitian ini sehingga memberi pedoman pada penelitian ini pembahasan permasalahan lebih fokus dan tidak terjadi penyimpangan dalam pelaksanaanya.

Dalam masalah-masalah yang dibahas pada penelitian ini, dapat menggunakan beberapa metode penyelesaiannya, di antaranya sebagai berikut :

1. Studi literatur

Studi literatur dilakukan dengan mencari informasi serta teori yang berhubungan dengan geometri jalan angkut berdasarkan referensi yang relevan.

\section{Observasi}

Penelitian ini dilakukan secara langsung dengan mengamati lokasi di penambangan pit 6 di PT XYZ terkait dengan permasalahan yang akan dibahas, antara lain :

a. Pengamatan terhadap daerah penambangan pit 6 di PT XYZ menentukan daerah lokasi pengambilan data.

b. Pengamatan dan pencatatan secara langsung terhadap faktor teknis di lapangan seperti dimensi geometri jalan angkut.

\section{HASIL DAN PEMBAHASAN 4.1 Hasil Pengamatan}

Dalam optimalisasi produksi batubara pada pit 6 PT XYZ, ada beberapa hal yang perlu dikaji, yaitu geometri jalan angkut, produksi aktual bulan April 2021 pada pit 6 dan cycle time (waktu edar) alat angkut batubara.

\subsubsection{Geometri Jalan Angkut Aktual}

a. Lebar Jalan Angkut Lajur Lurus Aktual

Jalan angkut batubara pada jalan lurus dari front ke stockrom diukur menggunakan alat ukur meteran. Jalan angkut lajur lurus dibagi menjadi 15 segmen, yaitu dari segmen front - A sampai stockrom dengan jarak total 2,5 km. Data lebar jalan per segmen dapat dilihat di tabel 4.1

Tabel 4.1 Lebar Jalan Angkut Pada Jalan Lurus Aktual Sebelum Perbaikan

\begin{tabular}{|c|c|c|c|}
\hline No. & Segmen Jalan & $\begin{array}{c}\text { Lebar Jalan } \\
(\mathrm{m})\end{array}$ & Keterangan \\
\hline 1 & Front - A & 13,3 & Ideal \\
\hline 2 & A - B & 9,8 & Ideal \\
\hline 3 & D - E & 11,8 & Ideal \\
\hline 4 & E - F & 8,8 & Ideal \\
\hline 5 & H - I & 12,1 & Ideal \\
\hline 6 & I - J & 11,5 & Ideal \\
\hline
\end{tabular}




\begin{tabular}{|c|c|c|c|}
\hline No. & Segmen Jalan & $\begin{array}{c}\text { Lebar Jalan } \\
(\mathrm{m})\end{array}$ & Keterangan \\
\hline 7 & $\mathrm{~J}-\mathrm{K}$ & 10 & Ideal \\
\hline 8 & $\mathrm{~K}-\mathrm{L}$ & 8,9 & Ideal \\
\hline 9 & $\mathrm{M}-\mathrm{N}$ & 10,4 & Ideal \\
\hline 10 & $\mathrm{~N}-\mathrm{O}$ & 7,3 & Tidak Ideal \\
\hline 11 & $\mathrm{P}-\mathrm{Q}$ & 9 & Ideal \\
\hline 12 & $\mathrm{~S}-\mathrm{T}$ & 10,5 & Ideal \\
\hline 13 & $\mathrm{~T}-\mathrm{U}$ & 5 & Tidak Ideal \\
\hline 14 & $\mathrm{U}-\mathrm{V}$ & 9,2 & Ideal \\
\hline 15 & Stockrom & 11,4 & Ideal \\
\hline
\end{tabular}

\subsubsection{Lebar Jalan Angkut Pada Tikungan Aktual}

Pada pengamatan yang dilakukan di lokasi penambangan jalan tikungan pada front ke stockrom memiliki 10 segmen, yaitu dari segmen B - C sampai segmen W - Stockrom, berdasarkan perhitungan penulis di lapangan yang digunakan pada jalan tikungan, yaitu 8,9635 meter atau 9 meter, data lebar jalan tikungan per segmen dapat dilihat di tabel 4.2.

Tabel 4.2 Lebar Jalan Angkut Pada Tikungan Sebelum Perbaikan

\begin{tabular}{|c|c|c|c|c|}
\hline No. & 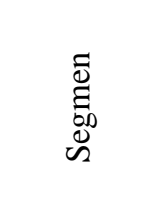 & $\begin{array}{l}\text { Lebar } \\
\text { Tikungan } \\
\text { di } \\
\text { Lapangan } \\
\text { (m) }\end{array}$ & $\begin{array}{c}\text { Lebar } \\
\text { Tikungan } \\
\text { Minimum } \\
\text { (m) }\end{array}$ & 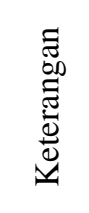 \\
\hline 1 & $B-C$ & 10,9 & 9 & Ideal \\
\hline 2 & $C-D$ & 10,7 & 9 & Ideal \\
\hline 3 & $F-G$ & 12 & 9 & Ideal \\
\hline 4 & $\mathrm{G}-\mathrm{H}$ & 11,8 & 9 & Ideal \\
\hline 5 & $\mathrm{~L}-\mathrm{M}$ & 9,7 & 9 & Ideal \\
\hline 6 & $\mathrm{O}-\mathrm{P}$ & 11,2 & 9 & Ideal \\
\hline 7 & $\mathrm{Q}-\mathrm{R}$ & 10 & 9 & Ideal \\
\hline 8 & $\mathrm{R}-\mathrm{S}$ & 10,4 & 9 & Ideal \\
\hline 9 & $\mathrm{~V}-\mathrm{W}$ & 9 & 9 & Ideal \\
\hline 10 & $\begin{array}{c}\mathrm{W}- \\
\text { Stockrom }\end{array}$ & 8,4 & 9 & $\begin{array}{l}\text { Tidak } \\
\text { ideal }\end{array}$ \\
\hline
\end{tabular}

\subsection{Kemiringan Jalan Angkut (Grade)}

Grade atau kemiringan memanjang jalan angkut dari front stockrom memiliki nilai yang starndar, yaitu tidak melebihi $8 \%$. Data kemiringan jalan persegmen dapat dilihat di tabel 4.4.
Tabel 4.4 Grade Atau Kemiringan

Memanjang Jalan dari Front ke Stockrom

\begin{tabular}{|c|c|c|c|c|c|c|}
\hline 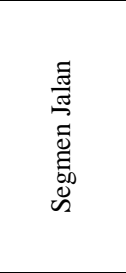 & 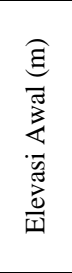 & 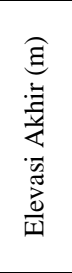 & 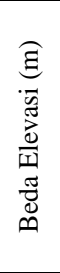 & 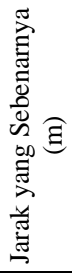 & 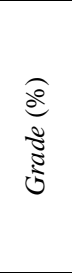 & 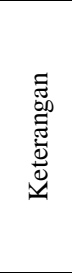 \\
\hline Front - A & 29,6 & 26,1 & $-3,5$ & 102,7 & $-3,4$ & Ideal \\
\hline A - B & 26,1 & 31,8 & 5,7 & 104 & 5,4 & Ideal \\
\hline B - C & 31,8 & 34,1 & 2,3 & 106 & 2,1 & Ideal \\
\hline C - D & 34,1 & 30,3 & $-3,8$ & 104 & $-3,6$ & Ideal \\
\hline D - E & 30,3 & 25,9 & $-4,4$ & 73,6 & -6 & Ideal \\
\hline$E-F$ & 25,9 & 31,5 & 5,6 & 109 & 5,1 & Ideal \\
\hline$F-G$ & 31,5 & 27,6 & $-3,9$ & 103 & $-3,7$ & Ideal \\
\hline $\mathrm{G}-\mathrm{H}$ & 27,6 & 25,1 & $-2,5$ & 100 & $-2,5$ & Ideal \\
\hline H - I & 25,1 & 27,1 & 2 & 96 & 2,08 & Ideal \\
\hline I - J & 27,1 & 28,8 & 1,7 & 81,5 & 2,08 & Ideal \\
\hline $\mathrm{J}-\mathrm{K}$ & 28,8 & 35,2 & 6,4 & 84 & 7,6 & Ideal \\
\hline$K-L$ & 35,2 & 29,5 & $-5,7$ & 102 & $-5,5$ & Ideal \\
\hline L - M & 29,5 & 23,7 & $-5,8$ & 105 & $-5,5$ & Ideal \\
\hline $\mathrm{M}-\mathrm{N}$ & 23,7 & 22,7 & -1 & 120 & $-0,83$ & Ideal \\
\hline $\mathrm{N}-\mathrm{O}$ & 22,7 & 21,8 & $-0,9$ & 109 & 0,82 & Ideal \\
\hline $\mathrm{O}-\mathrm{P}$ & 21,8 & 20,3 & $-1,5$ & 113 & $-1,32$ & Ideal \\
\hline$P$ - Q & 20,3 & 20,2 & $-0,1$ & 110 & $-0,1$ & Ideal \\
\hline Q - R & 20,2 & 19,4 & $-0,8$ & 109 & $-0,73$ & Ideal \\
\hline$R-S$ & 19,4 & 18,5 & $-0,9$ & 103 & $-0,87$ & Ideal \\
\hline$S-T$ & 18,5 & 20 & 1,5 & 103 & 1,4 & Ideal \\
\hline $\mathrm{T}-\mathrm{U}$ & 20 & 22,2 & 2,2 & 112 & 2 & Ideal \\
\hline $\mathrm{U}-\mathrm{V}$ & 22,2 & 24,7 & 2,5 & 104 & 2,4 & Ideal \\
\hline$V-W$ & 24,7 & 27,2 & 3 & 74 & 4 & Ideal \\
\hline $\begin{array}{c}\text { W - } \\
\text { Stockrom }\end{array}$ & 27,2 & 29,2 & 2 & 70 & 2,8 & Ideal \\
\hline
\end{tabular}

\subsection{Kemiringan Melintang (Cross Slope)}

Data (cross slope) atau kemiringan melintang persegmen dapat dilihat di tabel 4.5

Tabel 4.5 Cross Slope Per Segmen

\begin{tabular}{|c|c|c|c|c|c|c|}
\hline 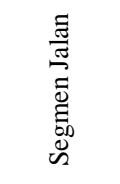 & 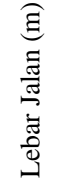 & $\underset{\infty}{Ð}$ & 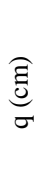 & $\begin{array}{l}\widehat{\Xi} \\
\sigma\end{array}$ & 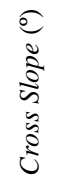 & 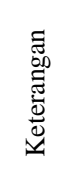 \\
\hline Front - A & 13,3 & 6,65 & 47 & 0,47 & 2,08 & Ideal \\
\hline$A-B$ & 9,8 & 4,9 & 35 & 0,35 & 2,20 & Ideal \\
\hline$D-E$ & 11,8 & 5,9 & 40 & 0,40 & 2,08 & Ideal \\
\hline$E-F$ & 8,8 & 4,4 & 38 & 0,38 & 2,70 & Ideal \\
\hline
\end{tabular}




\begin{tabular}{|c|c|c|c|c|c|c|}
\hline 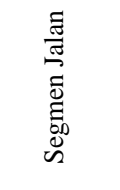 & 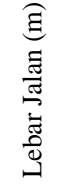 & छ్ & ह્व्ठ & $\begin{array}{l}\widehat{\Xi} \\
\sigma\end{array}$ & $\begin{array}{l}\sigma \\
\tilde{\Xi} \\
\vdots \\
\omega \\
\vdots \\
\vdots \\
\vdots\end{array}$ & 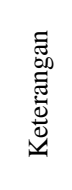 \\
\hline H - I & 12,1 & 6,05 & 47 & 0,47 & 2,41 & Ideal \\
\hline $\mathrm{I}-\mathrm{J}$ & 11,5 & 5,75 & 45 & 0,45 & 2,43 & Ideal \\
\hline $\mathrm{J}-\mathrm{K}$ & 10 & 5 & 34 & 0,34 & 2,08 & Ideal \\
\hline$K-L$ & 8,9 & 4,45 & 47 & 0,47 & 3,37 & Ideal \\
\hline$M-N$ & 10,4 & 5,2 & 40 & 0,40 & 2,38 & Ideal \\
\hline $\mathrm{N}-\mathrm{O}$ & 7,3 & 3,65 & 38 & 0,38 & 3,32 & Ideal \\
\hline$P-Q$ & 9 & 4,5 & 45 & 0,45 & 3,17 & Ideal \\
\hline$S-T$ & 10,5 & 5,25 & 45 & 0,45 & 2,68 & Ideal \\
\hline $\mathrm{T}-\mathrm{U}$ & 5 & 2,5 & 28 & 0,28 & 3,60 & Ideal \\
\hline $\mathrm{U}-\mathrm{V}$ & 9,2 & 4,6 & 40 & 0,40 & 2,72 & Ideal \\
\hline Stockrom & 11,4 & 5,7 & 48 & 0,48 & 2,63 & Ideal \\
\hline
\end{tabular}

\subsection{Penimbunan dan Pelapisan pada Jalan Angkut Batubara}

Penimbunan dan pelapisan jalan angkut batubara menggunakan material agregat, bertujuan untuk memperkuat lapisan jalan, mengurangi pengikisan yang terjadi akibat hujan serta meminimalisir adanya lumpur yang dapat menimbulkan slippery, Material agregat diangkut oleh dump truck Hino 500 Ranger, setelah itu diratakan menggungkan motor grade Caterpillar 120 dan dipadatkan menggunakan compactor Caterpillar CS533E agar material koral tidak berhamburan/berterbangan saat dilewati oleh alat yang melintasi jalan angkut batubara tersebut. Akan tetapi, proses penimbunan dan pelapisan jalan angkut tersebut bersamaan dengan proses produksi alat angkut batubara yang menyebabkan terjadinya waktu tunggu pada alat angkut batubara dan akan berpengaruh pada cycle time alat angkut battubara.

\subsection{Perhitungan Produksi Batubara}

Target produksi batubara di PT XYZ di pit 6 pada periode April 2021 sebesar 50.010 ton/bulan, melalui perhitungan dari penulis produksi batubara di PT XYZ yang dihasilkan aktual sebesar 40.044,837515 ton/bulan, maka target produksi batubara belum memenuhi target yang diinginkan. Melalui pengamatan dan perhitungan penulis di lapangan, maka dapat diasumsikan perbaikan penimbunan dan perlapisan pada jalan angkut batubara sangat berpengaruh pada cycle time alat angkut dan untuk jalan lurus di segmen $\mathrm{N}$ - $\mathrm{O}$ dan segmen $\mathrm{T}$ - U dan untuk jalan tikungan $\mathrm{W}$ - Stockrom, juga berpengaruh terhadap cycle time atau waktu tempuh. Semakin kecil waktu tempuh atau cycle time, maka akan menghasilkan produksi batubara semakin tinggi. Dari data perhitungan produksi batubara dari front ke stockrom pada pit 6 yang menggunakan alat angkut Hino 500 ranger sebesar 52.047,451194 ton/bulan. Maka target produksi di PT XYZ dapat mencapai target yang diinginkan setelah dilakukan perbaikan.

\section{KESIMPULAN}

Berdasarkan pembahasan yang sudah dilakukan, maka dapat disimpulkan sebagai berikut:

1. Hasil dari pengamatan di lapangan evaluasi geometri jalan angkut dari pit $6 \mathrm{ke}$ stockrom alat angkut yang digunakan, untuk jalan lurus aktual ada 2 segmen yang belum ideal yaitu segmen $\mathrm{N}-\mathrm{O}$ ukuran lebar jalan sebesar 7,3 meter dan segmen $\mathrm{T}$ - O ukuran lebar jalan sebesar 5 meter. Untuk jalan tikungan hasil dari pengamatan segmen di jalan tikungan yang belum ideal, yaitu segmen W - Stockrom memiliki lebar sebesar 8,4 meter.

2. Waktu edar alat angkut Hino 500 Ranger untuk mengangkut batubara dari front ke stockrom pada pit 6 sebelum perbaikan sebesar 19,21 menit, setelah dilakukan perbaikan jalan, yaitu 14,78 menit dengan demikian waktu edar alat angkut berkurang sebesar 4,42 menit.

3. Dari perhitungan di lapangan produksi alat angkut Hino 500 Ranger selama periode April 2021 dengan waktu edar sebesar 19,21 menit, didapatkan total produksi batubara di PT XYZ sebesar 40.044,837515 ton/bulan. Setelah dilakukan perbaikan jalan, didapatkan waktu edar alat angkut Hino 500 ranger sebesar 14,78 dan produksi batubara sebesar 52.047,451194 ton/bulan. 


\section{DAFTAR PUSTAKA}

American Association of State Highway And Tranportasion Official. 1990. A Policy On Geometric Design Of Highway and Street. Washington D.C.

Caterpilar. 2018. Specification and Application Handbook. 30 Edision Cat.

Hino. 2019. Specification and Application Handbook. 30 Edision Hino.

Indonesianto, Yanto. 2013. Pemindahan Tanah Mekanis. Yogyakarta: UPN "Veteran".

Kep.Men.ESDM No 1827 K/30/MEM/2018 Tentang Keselamatan dan Kesehatan Kerja Pertambangan Umum.

Projosumarto, Partanto. 1993. Pemindahan Tanah Mekanis. Bandung: Institut Teknologi Bandung.

Sukirman, Silvia. 1994. Dasar-dasar Perencanaan Geometri Jalan. Bandung: NOVA. 